Guest Editorial, part of a Special Feature on Exploring Feedbacks in Coupled Human and Natural Systems (CHANS)

\title{
Synthesis of human-nature feedbacks
}

\author{
Vanessa Hull $^{1}, \underline{\text { Mao-Ning Tuanmu }}^{1,2}$ and $\underline{\text { Jianguo Liu }}^{1}$
}

\begin{abstract}
In today's globalized world, humans and nature are inextricably linked. The coupled human and natural systems (CHANS) framework provides a lens with which to understand such complex interactions. One of the central components of the CHANS framework involves examining feedbacks among human and natural systems, which form when effects from one system on another system feed back to affect the first system. Despite developments in understanding feedbacks in single disciplines, interdisciplinary research on CHANS feedbacks to date is scant and often site-specific, a shortcoming that prevents complex coupled systems from being fully understood. The special feature "Exploring Feedbacks in Coupled Human and Natural Systems (CHANS)" makes strides to fill this critical gap. Here, as an introduction to the special feature, we provide an overview of CHANS feedbacks. In addition, we synthesize key CHANS feedbacks that emerged in the papers of this special feature across agricultural, forest, and urban landscapes. We also examine emerging themes explored across the papers, including multilevel feedbacks, time lags, and surprises as a result of feedbacks. We conclude with recommendations for future research that can build upon the foundation provided in the special feature.
\end{abstract}

Key Words: CHANS; feedback; policy; sustainability; telecoupling; time lag

\section{INTRODUCTION}

In the face of increased threats to sustainability around the world in recent decades, one of the central challenges faced by society is understanding and managing complex interactions between humans and nature. The Coupled Human and Natural Systems (CHANS) framework, also called social-ecological systems and human-environment systems frameworks, provides an effective means to characterize such interactions by providing a transdisciplinary approach to study complex systems (Liu et al. 2007a, b, Turner et al. 2007, Ostrom 2009). Such an approach is needed to tackle the increasingly complex global challenges of our time including biodiversity loss, climate change, deforestation, degradation of ecosystem services, disease spread, famine, and social unrest.

One of the central tenants of CHANS research calls for understanding feedbacks between human and natural systems. A feedback occurs "when a stimulus is fed back to its origin through one or a series of interactions" (Berryman 1989:231). The term "feedback" originates from literature on electric circuits dating back to the early 1900 s, when electric circuit loops were created to lead an electric output back to the input, resulting in either amplification or dampening of the signal (Bennett 1979). Today, it is appreciated that feedbacks can involve many different types of stimuli aside from electrical signals, including any type of matter, energy, or information. The interactions that allow a stimulus to be fed back to its origin can also take on many forms, such as biological, chemical, physical, or social interactions. Examples of diverse feedbacks include pituitary gland function (Hill and Tasker 2012), predator-prey cycles (Tirok et al. 2011), and the stock market (Betton et al. 2014). In fact, feedbacks are a part of many different disciplines such as electrical engineering (Vijay et al. 2012), biology (Pokhilko et al. 2012), computer science (Brun et al. 2009), finance (Betton et al. 2014), political science (Hermann 2012), management (Dahling et al. 2012), and education (Boud and Molloy 2013).

There are two main types of feedbacks, positive and negative. In this context, positive and negative do not refer to a value-based assessment of "good" or "bad," but rather to the type of change that takes place in the system. Positive feedbacks happen when a stimulus causes an amplification effect that reinforces change in the system after being fed back to its source. An example can be seen in some stock market dynamics, in which increases in investment in a given stock may result in further investments from other sources, which could in turn inspire progressively more investment and increase in value of the stock (Sentana and Wadhwani 1992, Betton et al. 2014). In contrast, negative feedbacks occur when a stimulus causes a dampening effect that decreases or reverses change in the system after being fed back to its source. An example is the predator-prey cycle in ecology, in which an increase in predators causes a decrease in available prey, which in turn results in a decline in the predator population (Berryman 1992, Tirok et al. 2011). Positive feedbacks are often associated with system destabilization and negative feedbacks with system stabilization (Plahte et al. 1995), but there are exceptions to this relationship (Cinquin and Demongeot 2002). For example, systems with multiple stable states can be stabilized with positive feedbacks and systems experiencing long time delays in the return of stimuli to the source can be destabilized by negative feedbacks (Cinquin and Demongeot 2002).

Another way to classify feedbacks is to characterize them as "tight" or "loose"(Levin 1999). The relative tightness or looseness of a feedback relates to the time lag in the system prior to the signal returning to the source. A tight feedback will involve a signal returning rapidly to the source, whereas a loose feedback takes place when a signal does not return to the source until after a long delay. Factors that can contribute to a time lag vary and include a geographical distance separating the source and destination or an institutional barrier preventing information flow in the system (Sundkvist et al. 2005). The duration of a time lag can have profound implications on system dynamics because tighter feedbacks can result in more rapid changes in the system, whereas looser feedbacks can often result in surprising effects that are not anticipated after a long delay (Sundkvist et al. 2005, Liu et al. 2007b).

Despite advancements in the understanding of feedbacks in recent years, the majority of research on feedbacks has been

${ }^{1}$ Center for Systems Integration and Sustainability (CSIS), Michigan State University, ${ }^{2}$ Department of Ecology and Evolutionary Biology, Yale University 
conducted on either the human or natural systems alone with little exploration of how feedbacks take place across human and natural components of complex systems because they are normally studied separately (Liu et al. 2007b). The CHANS framework can help overcome this shortcoming by highlighting how feedbacks link both human and natural components. Using this framework, feedbacks normally studied in natural systems such as logistic population growth curves, climate cycles, and nuclear reactions can be studied alongside feedbacks normally explored in human systems such as innovation spread, economic booms/depression, and educational evaluation. Integrating such research could reveal additional complexity in coupled systems with new feedbacks emerging between humans and nature that have not been characterized before. Such an approach is needed to improve our understanding of coupled systems and in turn improve ability to predict outcomes of potential future scenarios that affect stability and resilience of a given system.

The shortcoming associated with the discipline-specific nature of feedback research has begun to be overcome by recent studies on CHANS feedbacks (Rindfuss et al. 2008, He et al. 2009, Alberti et al. 2011). Some researchers have explored the role of feedbacks in land-use change, in which human actors or institutions change behaviors in response to changes in availability or quality of land, which in turn shapes future land-use patterns (Lambin and Meyfroidt 2010, Hersperger et al. 2011, Meyfroidt 2013a, b). Other examples can be seen in research on the role of feedbacks in the management of human-nature interactions in global food production chains (Sundkvist et al. 2005), the collapse of fisheries and fish habitat in response to overharvesting by humans (Altieri et al. 2013), and the success of payments for ecosystem services (PES) programs for conservation (Huber et al. 2013). Advances have also been made with respect to theoretical modeling, for example with understanding the contribution of human-nature feedbacks to system resilience (Bueno 2012). Despite these advances, the research on CHANS feedbacks to date has largely been site-specific (Chen et al. 2010, An et al. 2014). Integration across different types of systems and fields is needed to better understand underlying mechanisms driving CHANS feedbacks and how they can be used to promote sustainability in the future. We take the first step in this direction in a special feature entitled "Exploring Feedbacks in Coupled Human and Natural Systems (CHANS)."

\section{EXPLORING FEEDBACKS IN CHANS}

This special feature is one of the outcomes of a symposium entitled "NASA-MSU Symposium - Disentangling Diverse Drivers and Complex Dynamics of Coupled Human and Natural Systems (CHANS)" given at the 2012 U.S. Regional Association of the International Association for Landscape Ecology (USIALE) conference in Newport, Rhode Island (8-12 April 2012). The symposium was attended by a diverse group of researchers and practitioners from fields such as anthropology, demography, ecology, and geography, who came together to share and synthesize emerging approaches in CHANS. One of the common themes that became apparent in the symposium was the recurring examples of feedbacks and cutting-edge methods put forth for modeling them. Attendees of the symposium expressed a need for a published collection of research on this topic, which would help to unify disparate ideas and approaches that have not been fully integrated to date. This special feature seeks to fill this gap.
The special feature contains a total of seven papers examining feedbacks in a variety of different CHANS. Approaches used to characterize human-nature feedbacks draw on methods used across diverse fields including anthropology, economics, landscape ecology, and sociology. Examples consist of theoretical modeling using information and entropy theory (Mayer et al. 2014), tracking of environmental history records and identification of historical contingencies (Steen-Adams et al. 2015), and agent-based modeling (Zvoleff and An 2014). Feedbacks are also examined over a wide range of spatial scales, from pixels to entire landscapes; organization levels, from individuals to institutions; and temporal periods, from seasons to decades. Papers also provide real-world examples and applications that inform management and decision making in CHANS around the globe. Examples comprise management of protected areas (Zvoleff and An 2014), habitat restoration (Morzillo et al. 2014), and stormwater management (Shandas 2015).

Despite differences across the papers with respect to the study areas and approaches used, the papers share a common thread in recognizing that explicitly accounting for feedbacks helps to characterize the complexity of the CHANS and provides guidance on how to better manage intricately connected humannature couplings in the future. Furthermore, by bringing these papers together as a coherent special feature, several key themes and insights came to light that help inform the nascent field of research on CHANS feedbacks. We summarize the CHANS feedbacks discussed in the special feature and then turn to examining several important topics, including (1) multilevel effects, (2) time lags, and (3) surprises arising from CHANS feedbacks.

\section{OVERVIEW OF CHANS FEEDBACKS ACROSS LANDSCAPES}

Feedbacks covered in the special feature occurred across three main types of CHANS characterized by agriculture, forest, and urban landscapes (Table 1). Feedbacks in agricultural landscapes got to the heart of the complex human-nature processes governing how humans meet basic food needs. In some cases, humans abused and overused croplands and damaged soils, which later fed back to affect food security. Steen-Adams et al. (2015) discussed how increases in the size of farms in a tribal community resulted in a positive feedback of increased capital investment, increased intensification of agriculture, and in turn increased environmental degradation, e.g., soil erosion due to excessive irrigation. Farmers became trapped in a debt cycle and had difficulty keeping farms as family owned. Later on, soil erosion was reversed because of a negative feedback elicited by a wetland management program, which successfully reversed some of the earlier damage and discouraged overfarming. This type of negative agricultural feedback is not always manifested as a management measure because it could also be spurred by individual agents themselves if they change their own behavior in response to availability of agricultural resources. This occurred in Zvoleff and An (2014) in which households living in economically poor rural areas faced complex choices about how to maximize livelihoods. The authors found that households living in agricultural areas tended to delay marriage to maximize their opportunity to gain income via farming, an effect that decreased population growth and thus changed agricultural production over the long term. 
Table 1. Summary of coupled human and natural systems feedbacks explored in the special feature.

\begin{tabular}{lll}
\hline \hline Landscape & Positive & Negative \\
\hline Agriculture & Enlargement in the size of farms increases investment, & Wetland restoration spurred by soil erosion problems \\
& agricultural intensification, and environmental & reverses degradation in croplands (Steen-Adams et al. \\
& degradation (Steen-Adams et al. 2015). & 2015). \\
& Availability of agricultural land causes delay in marriage, \\
& which promotes future decline in population and pressure \\
& on agricultural land (Zvoleff and An 2014).
\end{tabular}

$\begin{array}{lll}\text { Forest } & \text { Fire suppression destabilizes a system by causing fuel }\end{array}$ accumulation in forests (Spies et al. 2014). Development around private forestlands encourages future development by opening up markets and influencing landowner attitudes (BenDor et al. 2014). Maladaptive policies promoting logging cause poverty in an indigenous community, which prompts locals to sell their land, causing further logging and degradation (Steen-Adams et al. 2015).

Urban
Fuel load control stabilizes forest volumes (Spies et al. 2014).

Timber harvesting markets encourage fuel load reduction (Spies et al. 2014).
Installation of new stormwater management facilities designed to improve water quality is spurred by past degradation of water resources (Shandas 2015).

Urban residents experience negative effects of rodents and initiate rodent control measures to decrease future rodent populations (Morzillo et al. 2014).
Some feedbacks discussed in the special feature took place in forest landscapes and explored complexities of human efforts to make use of forest resources to meet livelihood needs. Timber harvesting practices were not always sustainable, which not only harmed forest structure and forest quality but also fed back to threaten human livelihoods. For example, in Steen-Adams et al. (2015), members of a tribal community experiencing poverty sold their forestlands to obtain short-term economic gains without considering the long-term ramifications. Poverty only escalated when the resources and land dwindled, but timber harvesting continued to increase by logging companies, further perpetuating the positive feedback cycle of degradation. Similarly destabilizing (positive) feedbacks resulted in fire-prone forestlands discussed in Spies et al. (2014) when managers imposed measures that were not adapted to the system in question. When fire suppression was imposed in some forests, this short-term management strategy resulted in increased fuel loads and greater fire risk over the long term. In contrast, adaptive and stabilizing (negative) feedbacks resulted when agencies or landowners initiated measures to control fuel loads, altering their actions over time as they responded to changes that they observed in forests on the landscape.

Spies et al. (2014) also discussed how improved timber harvesting markets reduced fuel loads in fire-prone landscapes, thus stabilizing the system. Landowners were more likely to reduce fuel loads by harvesting if the market rewarded them for such activity. At the same time, landowner decisions may also be influenced by their neighbors and perceptions of the surroundings. For example, BenDor et al. (2014) discussed how the spread of urbanization in forestlands was often driven by development pressure via a positive feedback. In addition to creating new economic markets for development at fringe locations, increased presence of developed areas in their study area increased the propensity of forest owners to sell their land to allow for development because such changes harmed the owners' attitudes toward and value of the land.

Feedbacks taking place in urban landscapes were also explored in the special feature. Shandas (2015) describes a stormwater management program initiated to improve urban groundwater. He noted that in the initiation phase of the project, creation of management measures was part of a negative feedback. Institutions responded to the degradation in the drainage system by initiating policies to reverse the damage. However, maintenance of the stormwater system in a later phase required a constant positive feedback on the part of the residents, in which individuals in the communities needed to experience changes in their natural environment and recognize the benefits of the stormwater system to help maintain it over the long term as stewards.

A different type of feedback that also took place in urban landscapes involved interactions between humans and wildlife, processes that highlighted complexities in conflicts and coexistence within a shared space. For example, some landowners invested considerably in creation of backyard habitat for wildlife, efforts that were made in response to observation and appreciation for wildlife presence, e.g., for birdwatching, and with the intended desire to increase such presence in the future (Morzillo et al.2014). On the other hand, negative human-wildlife feedbacks also resulted, such as when increases in wildlife pests, e.g., rodents, inspired direct actions by humans to eradicate pest populations (Morzillo et al. 2014).

These CHANS feedbacks explored in the special feature demonstrate the variety and complexity of human-nature 
interactions in coupled systems. Some commonalities can be seen across studies with respect to how a positive feedback can snowball in a system and create catastrophic effects (e.g., profound loss of forest in a tribal community, complete transformation of forests to urban areas) or how a negative feedback can reverse previous patterns of unsustainable resource use (e.g., restore wildlife habitat or reduce fuel loads in a forest). Similar mechanisms are at play in driving the different types of feedbacks such as limited resources threatening human livelihood and dampening resource extraction (e.g., land, water, or food), economic market forces dictating positive feedbacks by promoting the trade or utilization of a resource (e.g., sale of crops, land, or timber), or policies put in place as negative feedbacks by humans who wish to better conserve the resource in the future (e.g., stormwater management, fuel load control measures). However, perhaps most meaningful are the nuances we found in different manifestations of feedbacks across diverse CHANS.

\section{MULTILEVEL EFFECTS}

One of the interesting threads running through several of the papers in this special feature dealt with differentiating feedbacks occurring at multiple organizational levels in the CHANS. Two levels that were commonly discussed concerned agents in the human system, i.e., individual actors and institutions. With respect to individuals, several of the papers discussed the importance of direct experiences by individuals in shaping behaviors and in turn the feedback as a whole. For instance, Spies et al. (2014) noted that individual landowners who had personal experiences with periodic fires were more likely to participate in effective fuel control measures. Similarly, Morzillo et al. (2014) explored how individual experiences with wildlife pests had a major role in shaping the pest control measures taken by agents that change wildlife populations and habitats across the landscape. Personal experiences of improved stormwater also played a main role in maintaining stormwater management in Shandas (2015). Differences in individual behaviors meant that the magnitude and intensity of the feedback varied over space in each example.

In contrast, institutions played more of a top-down role in shaping feedbacks. The role of institutions appeared in many cases to be dictated by the institution's responsiveness or access to information about the system. Several of the papers pointed out examples of institutions mismanaging systems, resulting in positive feedbacks that threatened the sustainability of the system, e.g., tribal governance dictating timber overharvesting in Steen-Adams et al. (2015) or top-down national policies supporting fire suppression across the U.S. in Spies et al. (2014). This type of mismanagement often arose as a result of lack of or incorrect information about the system or a disconnect between decision makers and system dynamics. As such, authoritarian institutions often appeared to be more prone to promoting positive feedbacks than autonomous ones (Steen-Adams et al. 2015).

Authors also pointed out successful top-down management examples with negative feedbacks achieving intended goals of reversing previous nonsustainable practices and in so doing improved sustainability in the system, e.g., adaptive management of forest fires in Spies et al. (2014). The value of such negative feedbacks for sustainability is illustrated in Mayer et al. (2014), who emphasized in their theoretical modeling work that a strengthening of negative feedbacks can make a system more robust and less vulnerable to collapse.

\section{TIME LAGS}

Another interesting topic that became apparent from the papers in the special feature was the role of time lags in the emergence and persistence of feedbacks. Time lags happen when a given effect does not emerge until after a long delay. Time lags inherently play a role in most feedbacks, simply because of the time required for the signal to return back to its source. The duration of the time lag may affect the nature of the feedback. Long time lags give rise to loose feedbacks and short time lags to tight feedbacks. For example, Zvoleff and An (2014) found that the feedback created from changing the timing of first birth of offspring in the household on land use was a loose feedback that did not emerge for several decades, probably because of the generation time required for offspring to mature. In this case, the feedback would not have been detected if the authors had limited their research to a shorter time frame. Time lags are especially relevant when taking a long-term historical perspective to investigating system dynamics, such as in Steen-Adams et al. (2015), who found that a lag in human population decline in response to forest degradation destabilized the system and affected long-term dynamics of human-forest relationships.

Time lags can also depend on the frequency of the human-nature interactions in question. For instance, Spies et al. (2014) explored human-nature interactions involving wildfires, which were relatively infrequent at any given location. Therefore, the long time lag and loose feedback between fire control measures initiated by humans and response of nature to these changes prevented individuals from seeing the value and effectiveness of such measures, thus discouraging the agents from learning about and reinforcing the feedback in the future. On the other hand, time lags that occur in conjunction with sustained human-nature interactions involving a repetitive series of consecutive feedbacks can give individual agents a longer duration of time to gain experience with the stimulus in question and improve their response to the stimulus in the future. This was the case for residents of an urban stormwater project who were more likely to want to engage in stewardship of the project after it had been in place for some time because they experienced desirable effects as a result of the ongoing tight feedback between their actions and the resulting consequences (Shandas 2015).

\section{SURPRISES}

Another common refrain throughout the papers contained in the special feature was that feedbacks can cause surprises to take place in a system. For example, Morzillo et al. (2014) discuss the phenomenon in which backyard habitat restoration initiated by humans in response to wildlife presence can not only cause a positive feedback with increases in bird populations, but can also increase presence of nontarget, and sometimes unwelcome, animals such as bears. This unintended consequence can in turn promote negative feedbacks in the future if humans retaliate in response to unwanted bear population increases. This observation highlights the complexity of CHANS and the importance of a holistic approach to understanding and managing a given system to attempt to anticipate such surprises.

Long-term studies and appreciation for the history of a system are also needed to better understand disturbance events that are often difficult to predict. Disturbances can occur unexpectedly and can impact feedbacks, in turn irrevocably altering future system states. Steen-Adams et al. (2015) refer to these as 
"historical contingencies" and give several examples, such as fire, labor shortages, and abrupt and ill-conceived policy shifts. Other examples include climate change, extreme weather events, and species invasions, e.g., pine beetle discussed in Spies et al. (2014) and blister rust in Steen-Adams et al. (2015). These findings highlight the need for researchers to take a long-term approach to understanding feedbacks and for managers to take an adaptive approach to implementing feedbacks as new changes arise.

\section{FUTURE DIRECTIONS}

This special feature makes a contribution to understanding and modeling feedbacks in CHANS, but more is needed to be done in the future. Areas for future research could take on the task of identifying key CHANS feedbacks in other types of landscapes aside from those we examined here, which would allow for a broader understanding of the diversity of feedbacks possible in coupled systems. In addition, several new methods that were proposed in the special feature to measure and model feedbacks in a particular system should be further tested on other systems. Examples include the entropy indices proposed by Mayer et al. (2014), the agent-based model for fire management adopted in Spies et al. (2014), and the conceptual framework for humanwildlife conflicts advocated by Morzillo et al. (2014). CHANS research as a whole can benefit from cross-site synthetic work that seeks to identify common patterns and generalizable traits of such complex systems (Carter et al. 2014).

The papers also provide guidance on specific topics to pursue in future research. Spies et al. (2014) highlight social networks as one mode in which information could be spread among agents in a system, which could potentially tighten a feedback loop. Further research is needed to explore this idea, specifically with respect to which types of networks promote system stabilization. Adaptive management is another theme raised in several papers (e.g., Speis et al. 2014, Steen-Adams et al. 2015) that is intricately linked to feedbacks because learning and changing management strategies over time can also tighten feedbacks. However, little is known about whether such changes alter magnitude of feedbacks and whether new feedbacks emerge from such changes.

New frontiers of CHANS feedback research should also examine interactions among different types of feedbacks in a single system, across different spatial scales and organizational levels, and among multiple CHANS in different parts of the globe via telecoupling processes, i.e., socioeconomic and environmental interactions over distances (see Liu et al. 2013, 2015, Liu 2014). We hope that this special feature will inspire further research on CHANS feedbacks to better understand and model CHANS and to tackle complex global challenges.

Responses to this article can be read online at: http://www.ecologyandsociety.org/issues/responses. $\mathrm{php} / 7404$

\section{Acknowledgments:}

We thank all of the contributing authors to the special feature for their time and dedication to this endeavor. We thank the National Science Foundation, National Aeronautics and Space Administration
(NASA), AgBioResearch, and Michigan State University for providing funding to support both the symposium at the 2012 U.S. Regional Association of the International Association for Landscape Ecology (US-IALE) conference and the development of the special feature inspired by the symposium.

\section{LITERATURE CITED}

Alberti, M., H. Asbjornsen, L. A. Baker, N. Brozovic, L. E. Drinkwater, S. A. Drzyzga, C. A. Jantz, J. Fragoso, D. S. Holland, T. A. Kohler, J. Liu, W. J. McConnell, H. D. G. Maschner, J. D. A. Millington, M. Monticino, G. Podestá, R. Gilmore Pontius, Jr., C. L. Redman, N. J. Reo, D. Sailor, and G. Urquhart. 2011. Research on coupled human and natural systems (CHANS): approach, challenges and strategies. Bulletin of the Ecological Society of America 92(2):218-228. http://dx.doi.org/10.1890/0012-9623-92.2.218

Altieri, A. H., M. D. Bertness, T. C. Coverdale, E. E. Axelman, N. C. Herrmann, and P. L. Szathmary. 2013. Feedbacks underlie the resilience of salt marshes and rapid reversal of consumerdriven die-off. Ecology 94(7):1647-1657. http://dx.doi. org/10.1890/12-1781.1

An, L., A. Zvoleff, J. Liu, and W. Axinn. 2014. Agent-based modeling in coupled human and natural systems (CHANS): lessons from a comparative analysis. Annals of the Association of American Geographers 104(4):723-745. http://dx.doi. org/10.1080/00045608.2014.910085

BenDor, T., D. A. Shoemaker, J.-C. Thill, M. A. Dorning, and R. K. Meentemeyer. 2014. A mixed-methods analysis of socialecological feedbacks between urbanization and forest persistence. Ecology and Society 19(3): 3. http://dx.doi.org/10.5751/ ES-06508-190303

Bennett, S. 1979. A history of control engineering, 1800-1930. Institution of Electrical Engineers, Stevenage, UK. http://dx.doi. org/10.1049/PBCE008E

Berryman, A. A. 1989. The conceptual foundations of ecological dynamics. Bulletin of the Ecological Society of America 70 (4):230-236.

Berryman, A. A. 1992. The origins and evolution of predatorprey theory. Ecology 73(5):1530-1535. http://dx.doi.org/10.2307/1940005

Betton, S., B. E. Eckbo, R. Thompson, and K. S. Thorburn. 2014. Merger negotiations with stock market feedback. Journal of Finance 69(4):1705-1745. http://dx.doi.org/10.1111/jofi.12151

Boud, D., and E. Molloy. 2013. Feedback in higher and professional education: understanding it and doing it well. Routledge, London, $\mathrm{UK}$.

Brun, Y., G. D. M. Serugendo, C. Gacek, H. Giese, H. Kienle, M. Litoiu, H. Müller, M. Pezzè, and M. Shaw. 2009. Engineering selfadaptive systems through feedback loops. Pages 48-70 in B. H. C. Cheng, R. de Lemos, H. Giese, P. Inverardi, and J. Magee, editors. Software engineering for self-adaptive systems. Springer, Berlin, Germany. http://dx.doi.org/10.1007/978-3-642-02161-9_3

Bueno, N. P. 2012. Assessing the resilience of small socioecological systems based on the dominant polarity of their feedback structure. System Dynamics Review 28(4):351-360. http://dx.doi.org/10.1002/sdr.1476 
Carter, N. H., A. Viña, V. Hull, W. J. McConnell, W. Axinn, D. Ghimire, and J. Liu. 2014. Coupled human and natural systems approach to wildlife research and conservation. Ecology and Society 19(3): 43. http://dx.doi.org/10.5751/ES-06881-190343

Chen, X., F. Lupi, A. Viña, G. He, and J. Liu. 2010. Using costeffective targeting to enhance the efficiency of conservation investments in payments for ecosystem services. Conservation Biology 24:1469-1478. http://dx.doi.org/10.1111/j.1523-1739.2010.01551. $\underline{\mathrm{X}}$

Cinquin, O., and J. Demongeot. 2002. Roles of positive and negative feedback in biological systems. Comptes Rendus Biologies 325(11):1085-1095. http://dx.doi.org/10.1016/S1631-0691 (02)01533-0

Dahling, J. J., S. L. Chau, and A. O'Malley. 2012. Correlates and consequences of feedback orientation in organizations. Journal of Management 38(2):531-546. http://dx.doi.org/10.1177/01492$\underline{06310375467}$

He, G., X. Chen, S. Bearer, M. Colunga, A. Mertig, L. An, S. Zhou, M. Linderman, Z. Ouyang, S. Gage, S. Li, and J. Liu. 2009. Spatial and temporal patterns of fuelwood collection in Wolong Nature Reserve: implications for panda conservation. Landscape and Urban Planning 92(1):1-9. http://dx.doi.org/10.1016/j. landurbplan.2009.01.010

Hermann, C. F. 2012. When things go wrong: foreign policy decision making under adverse feedback. Routledge, London, UK.

Hersperger, A. M., M.-P. Gennaio, P. H. Verburg, and M. Bürgi. 2011. Feedback loops in conceptual models of land change: lost in complexity? Ecology and Society 16(2): r1. [online] URL: http:// www.ecologyandsociety.org/vol16/iss2/resp1/

Hill, M. N., and J. G. Tasker. 2012. Endocannabinoid signaling, glucocorticoid-mediated negative feedback, and regulation of the hypothalamic-pituitary-adrenal axis. Neuroscience 204:5-16. http://dx.doi.org/10.1016/j.neuroscience.2011.12.030

Huber, R., S. Briner, A. Peringer, S. Lauber, R. Seidl, A. Widmer, F. Gillet, A. Buttler, Q. B. Le, and C. Hirschi. 2013. Modeling social-ecological feedback effects in the implementation of payments for environmental services in pasture-woodlands. Ecology and Society 18(2): 41. http://dx.doi.org/10.5751/ ES-05487-180241

Lambin, E. F., and P. Meyfroidt. 2010. Land use transitions: Socio-ecological feedback versus socio-economic change. Land Use Policy 27(2): 108-118. http://dx.doi.org/10.1016/j. landusepol.2009.09.003

Levin, S. A. 1999. Fragile dominion: complexity and the commons. Perseus, Reading, Massachusetts, USA.

Liu, J. 2014. Forest sustainability in China and implications for a telecoupled world. Asia \& the Pacific Policy Studies 1(1):230-250. http://dx.doi.org/10.1002/app5.17

Liu, J., T. Dietz, S. R. Carpenter, M. Alberti, C. Folke, E. Moran, A. N. Pell, P. Deadman, T. Kratz, J. Lubchenco, E. Ostrom, Z. Ouyang, W. Provencher, C. L. Redman, S. H. Schneider, and W. W. Taylor. 2007a. Complexity of coupled human and natural systems. Science 317(5844):1513-1516. http://dx.doi.org/10.1126/ science. 1144004
Liu, J., T. Dietz, S. R. Carpenter, C. Folke, M. Alberti, C. L. Redman, S. H. Schneider, E. Ostrom, A. N. Pell, J. Lubchenco, W. W. Taylor, Z. Ouyang, P. Deadman, T. Kratz, and W. Provencher. 2007b. Coupled human and natural systems. AMBIO: A Journal of the Human Environment 36(8):639-649.

Liu, J., V. Hull, M. Batistella, R. DeFries, T. Dietz, F. Fu, T. W. Hertel, R. C. Izaurralde, E. F. Lambin, S. Li, L. A. Martinelli, W. J. McConnell, E. F. Moran, R. Naylor, Z. Ouyang, K. R. Polenske, A. Reenberg, G. de Miranda Rocha, C. S. Simmons, P. H. Verburg, P. M. Vitousek, F. Zhang, and C. Zhu. 2013. Framing sustainability in a telecoupled world. Ecology and Society 18(2): 26. http://dx.doi.org/10.5751/ES-05873-180226

Liu, J., H. Mooney, V. Hull, S. J. Davis, J. Gaskell, T. Hertel, J. Lubchenco, K. C. Seto, P. Gleick, C. Kremen, and S. Li. 2015. Systems integration for global sustainability. Science 347(6225). http://dx.doi.org/10.1126/science. 1258832

Mayer, A. L., R. P. Donovan, and C. W. Pawlowski. 2014. Information and entropy theory for the sustainability of coupled human and natural systems. Ecology and Society 19(3): 11. http:// dx.doi.org/10.5751/ES-06626-190311

Meyfroidt, P. 2013a. Environmental cognitions, land change and social-ecological feedbacks: local case studies of forest transition in Vietnam. Human Ecology 41(3):367-392. http://dx.doi. org/10.1007/s10745-012-9560-X

Meyfroidt, P. 2013b. Environmental cognitions, land change, and social-ecological feedbacks: an overview. Journal of Land Use Science 8(3):341-367. http://dx.doi.org/10.1080/1747423X.2012.667452

Morzillo, A. T., K. M. de Beurs, and C. J. Martin-Mikle. 2014. A conceptual framework to evaluate human-wildlife interactions within coupled human and natural systems. Ecology and Society 19(3): 44. http://dx.doi.org/10.5751/ES-06883-190344

Ostrom, E. 2009. A general framework for analyzing sustainability of social-ecological systems. Science 325:419-422. http://dx.doi.org/10.1126/science.1172133

Plahte, E., T. Mestl, and S. W. Omholt. 1995. Feedback loops, stability and multistationarity in dynamical systems. Journal of Biological Systems 3(02):409-413. http://dx.doi.org/10.1142/ $\underline{\mathrm{S} 0218339095000381}$

Pokhilko, A., A. P. Fernández, K. D. Edwards, M. M. Southern, K. J. Halliday, and A. J. Millar. 2012. The clock gene circuit in Arabidopsis includes a repressilator with additional feedback loops. Molecular Systems Biology 8(1):574. http://dx.doi. org/10.1038/msb.2012.6

Rindfuss, R. R., B. Entwisle, S. J. Walsh, L. An, N. Badenoch, D. G. Brown, P. Deadman, T. P. Evans, J. Fox, J. Geoghegan, M. Gutmann, M. Kelly, M. Linderman, J. Liu, G. P. Malanson, C. F. Mena, J. P. Messina, E. F. Moran, D. C. Parker, W. Parton, P. Prasartkul, D. T. Robinson, Y. Sawangdee, L. K. Vanwey, and P. H. Verburg. 2008. Land use change: complexity and comparisons. Journal of Land Use Science 3(1):1-10. http://dx.doi. org/10.1080/17474230802047955

Sentana, E., and S. Wadhwani. 1992. Feedback traders and stock return autocorrelations: evidence from a century of daily data. Economic Journal 102:415-425. http://dx.doi.org/10.2307/2234525 
Shandas V. 2015. Neighborhood change and the role of environmental stewardship: a case study of green infrastructure for stormwater in the City of Portland, Oregon, USA. Ecology and Society 20(3):16. http://dx.doi.org/10.5751/ES-07736-200316.

Spies, T. A., E. M. White, J. D. Kline, A. P. Fischer, A. Ager, J. Bailey, J. Bolte, J. Koch, E. Platt, C. S. Olsen, D. Jacobs, B. Shindler, M. M. Steen-Adams, and R. Hammer. 2014. Examining fire-prone forest landscapes as coupled human and natural systems. Ecology and Society 19(3): 9. http://dx.doi.org/10.5751/ ES-06584-190309

Steen-Adams, M. M., N. Langston, M. D. O. Adams, and D. J. Mladenoff. 2015. Historical framework to explain long-term coupled human and natural system feedbacks: application to a multiple-ownership forest landscape in the northern Great Lakes region, USA. Ecology and Society 20(1): 28. http://dx.doi. org/10.5751/ES-06930-200128

Sundkvist, A., R. Milestad, and A. Jansson. 2005. On the importance of tightening feedback loops for sustainable development of food systems. Food Policy 30(2):224-239. http:// dx.doi.org/10.1016/i.foodpol.2005.02.003

Tirok, K., B. Bauer, K. Wirtz, and U. Gaedke. 2011. Predatorprey dynamics driven by feedback between functionally diverse trophic levels. PLoS ONE 6(11):e27357. http://dx.doi. org/10.1371/journal.pone.0027357

Turner II, B. L., E. F. Lambin, and A. Reenberg. 2007. The emergence of land change science for global environmental change and sustainability. Proceedings of the National Academy of Sciences 104:20666-20671. http://dx.doi.org/10.1073/pnas.0704119104

Vijay, R., C. Macklin, D. H. Slichter, S. J. Weber, K. W. Murch, R. Naik, A. N. Korotkov, and I. Siddiqi. 2012. Stabilizing Rabi oscillations in a superconducting qubit using quantum feedback. Nature 490(7418):77-80. http://dx.doi.org/10.1038/nature11505

Zvoleff, A., and L. An. 2014. The effect of reciprocal connections between demographic decision making and land use on decadal dynamics of population and land-use change. Ecology and Society 19(2): 31. http://dx.doi.org/10.5751/ES-06243-190231 